\title{
Ensino de enfermagem no Rio Grande do Sul apartir de 1950
}

\author{
Teaching of nursing in Rio Grande do Sul in the 1950 \\ Enseñanza de enfermería en Rio Grande do Sul a partir del 1950
}

\section{Valéria Lamb Corbellini', Beatriz Sebben Ojeda', Beatriz Regina Lara dos Santos', Marion Creutzberg'}

'Pontifícia Universidade Católica do Rio Grande do Sul. Curso de Graduação em Enfermagem. Porto Alegre, RS

Submissão: 12/12/2008

Aprovação: 05/07/2010

\section{RESUMO}

Essa pesquisa teve como objetivo analisar como o ensino de graduação na enfermagem, no Rio Grande do Sul construiu o seu saber, desde o primeiro curso, a partir da década de 1950. O estudo envolveu enfermeiras docentes Que vivenciaram esse período da história e, para análise documental, foi utilizada a análise de discurso. Os dados indicam, dentre eles, o currículo mais integrado Que busca articular teoria/prática sem fragmentação do saber e a relação ensino-aprendizagem, na Qual professor e aluno são sujeitos desse processo.

Descritores: Educação em enfermagem; Ensino; História da enfermagem

\section{ABSTRACT}

The purpose of this research was to analyze how the undergraduate teaching of nursing in Rio Grande do Sul has constructed its knowledge, since the first course, as of the decade of 1950s. The survey has involved teaching nurses who have lived such period of our history, and the discourse analysis has been utilized for the documental analysis. The information data indicate, among them, the most integrated curriculum that seeks articulating theory/practice without fragmenting the knowledge and the teaching-learning relationship, wherein professors and students are subjects of such procedure.

Key words: Education, nursing; Teaching; History of nursing.

\section{RESUMEN}

Esta investigación tuvo como objetivo analizar como la enseñanza de la pregrado de Enfermería en Río Grande do Sul construyó su saber, desde el primer curso, a partir de la década de 1950. El estudio integró enfermeras docentes Que vivenciaron ese periodo de la historia y, para el análisis documental, fue utilizado el análisis del discurso.Los datos indican, entre ellos, el curriculum más integrado Que busca articular teoría y práctica sin fragmentación del saber y la relación enseñanza aprendizaje, en la cuál el profesor y el alumno son sujetos de ese processo.

Descriptores: Educación en enfermería; Enseñanza; Historia de la enfermería. 


\section{INTRODUÇÃO}

O Brasil, na década de 1950, tanto no plano sóciopolítico como econômico era essencialmente agrícola, sendo que o setor agrárioexportador era o cafeeiro. Nessa época, as endemias e as epidemias assolavam o País ${ }^{(1)}$. O perfil epidemiológico, com alta incidência de varíola, difteria, coqueluche, tétano, sarampo e doenças sexualmente transmissíveis decorrente da falta de profissionais capacitados, da precariedade do saneamento básico e da falta de conhecimento da população, o Que impedia a adesão à vacinação(2)

No início do Século XX, em cidades brasileiras portuárias, havia um descaso político sobre o alto índice de mortalidade infantil e de doenças infecto-contagiosas Que matavam grande número de pessoas. Paralelamente, países que comercializavam com o Brasil ameaçavam, constantemente, parar com as exportações, caso persistissem as epidemias, as Quais colocavam em risco as tripulações Que aportavam e a população de origem. Tal pressão gerou uma mudança nas diretrizes sanitárias, Que passaram a ser de cunho educativo e preventivo ${ }^{(3)}$.

Nesse contexto, foi criada a primeira Escola de Enfermagem, no Rio Grande do Sul (RS), na Universidade Federal do Rio Grande do Sul (UFRGS), em 4 de dezembro de 1950 que esteve vinculada à Faculdade de Medicina, até $1968^{(4)}$. Até a constituição da primeira turma de Graduação em Enfermagem, nessa década, no RS, havia visitadoras sanitárias, Que atuavam na Saúde Pública e tinha como objetivo, realizar visitas domiciliares, orientando as famílias sobre as vacinas, princípios de higiene, bem como sobre medidas preventivas das doenças transmissíveis, encaminhamento de gestantes à Unidade Sanitária para o acompanhamento pré-natal, entre outros $^{(2)}$.

Um dos discursos da época era o enfoque ao ensino de Enfermagem para a Saúde Pública, porém, não foi o Que na prática se instituiu, pois ele iniciou permeado pelo moralismo da época, centrado no conhecimento de patologias, voltado para o atendimento hospitalar, curativo e subalterno ao trabalho e modelo médico ${ }^{(5)}$.

Desta forma, para ir em busca da visibilidade de saberes e práticas, encobertos na trajetória do ensino de graduação em enfermagem, este estudo teve como objetivo analisar como se deu o ensino, a partir das práticas discursivas, presentes desde a primeira escola de enfermagem, no RS, e, por meio de momentos, mesmo Que dispersos, conhecer as várias interfaces do ensino Que perpassaram esses anos.

\section{MÉTODO}

Trata-se de um estudo Qualitativa baseada na Arqueologia, Genealogia e na História Oral. Pelo método arQueológico, as ordens de saber são encontradas na formação discursiva de uma determinada época. Pelo método genealógico, pode-se criticar e descrever a trajetória das transformações discursivas. A História oral dispõe de um meio de transformar, tanto o seu conteúdo, Quanto sua finalidade, revelando novos campos de investigação.

O estudo envolveu três enfermeiras, com idade acima de 60 anos, Que vivenciaram esse período da história como graduandas de enfermagem e, após, como docentes em um curso de graduação em enfermagem.
A entrevista narrativa foi uma das modalidades de coleta. Outras formas de trilhar, em busca de novos enunciados, ocorreram por análise documental, a partir da década de 1950, sempre baseada em Questionamentos do presente ${ }^{(6)}$. Para análise documental, elegeuse a análise de discurso ${ }^{(7)}$.

A pesquisa foi aprovada pelo Comitê de Ética e Pesquisa da PUCRS e, respeitando os aspectos éticos, conforme Resolução 196/96 do Conselho Nacional de Saúde (1996) foi apresentado a cada enfermeira o Termo de Consentimento Livre e Esclarecido. Após a leitura, o termo foi assinado pela participante e pela peseuisadora. As entrevistas foram gravadas e transcritas pela pesquisadora.

\section{RESULTADOS E DISCUSSÃO}

\section{Geografia do ensino de enfermagem no Rio Grande do Sul: definindo rotas, formas e produções presentes}

Em 1938, no RS, a enfermeira Izaura Barbosa Limaa, Que trabalhava no Departamento Nacional de Saúde (RJ), foi convidada pelo Dr. José Bonifácio Paranhos da Costa, Diretor do Departamento Estadual de Saúde, a organizar os serviços de saúde do estado, principalmente na Área da Enfermagem, pois o Estado apresentava como indicadores de saúde, alta incidência de morbidade e mortalidade infantil, Que poderiam ser erradicadas ou controladas por ações imunizantes. Exemplos como São Paulo, Rio de Janeiro e Minas Gerais, onde já existiam enfermeiras, encontravam resolutividade para esses problemas ${ }^{(2)}$. Rosa-dos-Ventos verbaliza esse momento:

[...] Izaura Barbosa Lima, veio para o RS e começou um curso para preparar visitadoras sanitárias Que eram uma espécie de auxiliares de Enfermagem em Saúde Pública. Eu iniciei na Enfermagem como visitadora sanitária. D. Isaura, Que era de Saúde Pública, veio aqui para o Estado implantar esse curso, pois o Estado, naquela época, vivia com grandes epidemias e precisava de pessoas que fizessem visitas domiciliares.

Brisa também expressa, em sua fala, a situação epidemiológica da época:

Concluí o ginásio naquela época e como não existia Escola de Enfermagem no Estado, eu fui fazer o curso de visitadora sanitária. [...] os indicadores de saúde eram péssimos, existia a maior incidência de doenças venéreas, de tuberculose e de toxicoses, a mortalidade infantil era altíssima.

A exemplo de outros estados, a visitadora sanitária surgiu por uma necessidade específica de contribuir para a diminuição de elevada taxa de mortalidade e epidemias Que interferiam no desenvolvimento econômico do RS. Poder-se-ia ousar inferir Que ela chegou para ocupar um espaço de poder, mas, ao mesmo tempo, ou paradoxalmente, um espaço de não poder, pois ela nasceu sob

azaura Barbosa Lima, diplomou-se em 1925 pela escola Anna Nery, Rio de Janeiro. Trabalhou no Departamento Nacional de Saúde Pública (RI) e retornou para o RS em 1938 para organizar os serviços de saúde deste estado, permanecendo cinco anos. Criou o curso de Visitadora Sanitária em Porto Alegre. 
ordens médicas

Rosa-dos-Ventos, ao verbalizar a necessidade de pessoas Que fizessem visita domiciliar traduziu um enunciado de Que a solução para mudar o perfil epidemiológico da época seria a de ter profissionais que desenvolvessem essa atividade, que era exercida por médicos sanitaristas. Entretanto, os médicos perceberam Que não era sua função realizar a visita domiciliar, considerando-a imprópria para a sua profissão. Alguns deles Que fizeram estágio nos Estados Unidos e lá conheceram a figura da enfermeira sanitarista, ao retornarem, propuseram o treinamento de profissionais para exercer esse papel ${ }^{(1)}$.

Quando eles buscaram a figura da enfermeira para exercer atividades Que julgavam ser impróprias para a sua profissão, traduziram, com essa atitude, um saber sujeitado, o Que para Foucault ${ }^{(8)}$, estava incluído em uma série de saberes desqualificados, ingênuos, hierarquicamente inferiores, abaixo do nível do conhecimento ou da cientificidade requerida.

Para entender melhor por Que o Curso Superior de Enfermagem chegou, nesse período, para suprir uma necessidade importante na época, mas negada pela equipe médica, e até mesmo desqualificada por ela, é preciso analisar historicamente, conforme Foucault, como esses regimes de verdades foram produzidos no interior de discursos e poreue a prática discursiva, utilizada nesse período, reflete, ainda hoje, a hegemonia médica nas relações de saberes. "[...] não se busca aqui, o certo ou o errado, o bom ou o mau, mas entender como o sujeito se constitui a si mesmo, por meio de práticas sociais Que se instituem como jogos de verdade"(9).

Ao se referir à Questão de sujeito, Foucault buscou criar uma história de como os seres humanos, em nossa cultura, tornam-se sujeitos. Nesse sentido, ele estudou três modos de objetivação para essa transformação: a) as diferentes formas de investigação Que tentam atingir o estatuto de Ciência, ou seja, a objetivação do sujeito produtivo, do sujeito Que trabalha, o sujeito do discurso na Filosofia, na Linguística ou o simples fato de o sujeito estar vivo na História natural; b) a objetivação do sujeito nas práticas divisórias, em Que ele é dividido, no seu interior e em relação aos outros, exemplo, o louco e o são, o doente e o sadio, o bom e o mau, entre outros. O modo pelo Qual o ser humano torna-se um sujeito como objeto para si mesmo, pelo Qual ele é induzido a observarse, analisar-se, reconhecer-se como domínio do seu saber ${ }^{(10)}$.

Neste sentido, se Questiona se a Enfermagem, ao criar a sua própria história, tornando-se sujeito de si mesma, não criou, em seu discurso, práticas divisórias de Que para a medicina caberia o saber e, para a enfermagem, o fazer e, também, se nessa relação de saber/fazer, ambos ocuparam seus espaços e coube à medicina definir Quais os regimes de verdades Que estariam presentes em cada prática discursiva da enfermagem.

Além disso, ao buscar higienizar, ela cria uma área de saber e, consequentemente, uma área de poder, mas que nasce sob a guarda médica. Assim, ela se constitui paradoxalmente num espaço de relação de poder e de não poder.

É nesta perspectiva Que, ao ir em busca de respostas ou rupturas se adota, como rota, as décadas de 1930/1940, pois foi nesse período, Que se iniciou a transição da Enfermagem pré-profissional para a profissional, no RS. Com a Escola de Enfermagem da UFRGS, em 1950, ela se profissionaliza.

Uma análise, a partir da década de 1930, Quando o País buscou sair da visão agrária exclusiva, mesmo Que sucinta, pode auxiliar a melhor entender as condições estratégicas desencadeadoras ou, pelo menos, provocadoras ou mantenedoras de relações de poder e criação de relações de saber Que se mantêm e se perpetuam até os dias de hoje.

No governado de Flores da Cunha (1934-1937), o RS tinha uma economia agropecuária e o charque era o principal produto de exportação. Na Agricultura, o arroz e o trigo eram as culturas predominantes. Na implantação do Estado Novo, no Brasil (19371945), o modelo econômico do RS continuava com uma Economia agropecuária. Tanto no setor agrícola, como na pecuária, a remuneração era muito baixa, favorecendo o êxodo rural. As cidades não absorviam todas as pessoas vindas do campo, formando-se vilas marginais, nas periferias, sobrevivendo seus habitantes, em um nível de subempregos ${ }^{(1)}$.

Na década de 1940, a Economia ainda centrada na agropecuária estava em crise. As chareueadas iniciaram o processo de frigorização. Na Agricultura, ao lado da lavoura de arroz, cresceu a mecanização do trigo. Continuava, nesse período, o crescimento do êxodo rural para as cidades, aumentando o número de desempregados e vilas nas periferias ${ }^{(11)}$.

As crises econômicas, na década de 1950, se refletiam na Área da Saúde. As Santas Casas de Misericórdia eram voltadas exclusivamente para os pobres, os excluídos. Os ricos tinham seu médico da família e cuidadores a domicílio e, Quando precisavam, iam se tratar no Rio de Janeiro, São Paulo, Europa ou nos EUA ${ }^{(2)}$.

Os postos de saúde da época eram voltados para a classe menos favorecida economicamente, situação essa expressa na fala de Sol:

Eu me lembro Que os nossos professores nos convidavam, como alunas, para ir, inclusive na casa deles fazer a vacina nos seus filhos, porque não havia nos consultórios e nem sempre nos postos e havia preconceito de Quem ia ao posto de saúde era o pobre. Então a Saúde Pública era mais voltada para saneamento básico ou Quando havia campanhas, pois a vacina SABIN apareceu no ano em Que me formei.

Nos dias atuais essas práticas pouco mudaram, ou seja, a grande parcela que utiliza as Unidades Sanitárias são os menos favorecidos. São bens de serviço Que permanecem, embora todo um discurso, vinculado a segmentos privilegiados da população. Antes, conforme referendou Sol, as crianças de classe social mais favorecida recebiam sua vacina em casa. Com o passar dos tempos, clínicas particulares de vacinação, assim como os consultórios particulares, começaram a fazer parte do cenário de saúde. Hoje, parte da população, com condições econômicas favoráveis, preferem pagar por uma vacina, a se expor à rotina de uma Unidade Básica de Saúde.

Entretanto, grande parcela da população já percebe a saúde como um direito seu, porém, essa apropriação ainda não conseguiu garantir a credibilidade do setor público, fazendo com Que Quase todos os dissídios coletivos incluam em suas cláusulas de trabalho convênios com empresas médicas, mantendo, assim, a hegemonia corporativa do privado $^{(12)}$.

Ao serem as participantes Questionadas sobre o porquê de fazerem o Curso de Enfermagem, o desejo foi o mesmo para duas delas. Eram visitadoras sanitárias e Queriam cursar Enfermagem para seguir na profissão. Rosa-dos-Ventos, relata Que 
[...] em 1945, a enfermeira Izaura Barbosa Lima, Que era de Saúde Pública, veio para o RS e começou a preparar auxiliares de Saúde Sanitária, que eram uma espécie de auxiliares de Enfermagem em saúde pública. Foi neste período, que fui convidada por ela, para fazer o Curso de Enfermagem e formei-me em 1948.

Já Brisa, recebeu o convite de um médico Que lhe comunicou Que a UFRGS abriria o Curso de Enfermagem no RS.

[...] Estava me preparando para fazer Enfermagem no Rio, no $2^{\circ}$ semestre de 1949, Quando apareceu Dr. Paulo Becker, Que era supervisor da Área da Saúde, do Departamento Estadual de Saúde. Dando uma boa notícia, ele falou: 'A Sra. não Quer fazer Enfermagem?' Eu disse: 'estou me preparando para fazer no Rio, porQue não existe na Região Sul', e ele: 'eu vou criar em Porto Alegre, o professor Guerra, Diretor da Medicina da UFRGS, já solicitou a criação de um curso de Enfermagem, Que funcionará a partir de 1950, já poderão se inscrever os candidatos para esse ano'.

Além disso, Rosa-dos-Ventos verbalizou Que, ao ser convidada a fazer o Curso de Graduação em Enfermagem, o Que mais contava na seleção era se a candidata vinha de uma "boa família" e isso era levado muito em consideração, pois

[...] como o nome Enfermagem dava a idéia de que Qualquer pessoa podia cuidar de uma pessoa e [...] então selecionava muito.

O discurso presente na época, conforme ela referendou, era de Que Qual Quer uma que cuidava de doente no hospital era enfermeira, fazendo com que a luta inicial fosse muito grande, pois,

[...] Não era reconhecida dentro do Que se acreditava ser enfermeira; entre ser enfermeira e faxineira era Quase a mesma coisa. Era assim: a pessoa ia fazer serviços no hospital e tanto cuidava do doente como já cuidava da limpeza. (Rosa dos Ventos)

O processo de seleção das candidatas ao curso de enfermagem era muito severo. A finalidade era mudar o Quadro desfavorável perante a sociedade, pois o modelo vigente, nessa época, traduzia uma enfermagem desqualificada e Quando uma "moça de boa família" decidia fazer o curso de Enfermagem, era Questionada do porQuê não escolhia outra profissão. Rosa-dos-Ventos exemplifica essa Questão ao relatar uma situação vivenciada por ela:

Quando eu viajei, naQuela época, de navio, meu pai e minha mãe tinham uma pessoa da família Que ia viajar de navio. Então, ele me representou, viajou junto, foi no mesmo camarote e ele Querendo saber o que eu iria fazer, perguntou o que eu iria estudar. E eu disse: eu vou fazer Enfermagem. 'O Que menina? Enfermagem, Que é isso, eu pensei Que tu fosses fazer Medicina ou Artes'.

Da mesma forma Sol Quando Questionada pelo seu pai sobre a escolha profissional disse:

[... pai, eu já sei o Que vou ser, vou ser enfermeira! E o meu pai disse assim: 'ah! Tu és muito inteligente, tu és muito culta, tens Que ser engenheira, 'e eu era boa de lábia, advogada'. Eu disse 'não', e ele falou: 'tu não Queres ser professora?' E eu disse: 'sim e Quero ser enfermeira!'

A história tem nos mostrado, vários "modelos" Que foram sendo (des)construídos ao longo do tempo. Essas mudanças sempre estiveram, não somente ancoradas no momento político e social em Que o País se encontra, mas também vinculada a processos de outras épocas que ainda nos influenciam, tais como a exigência com relação ao corpo da enfermeira, da sua retidão moral, como reverberações, ainda, do estilo nigthtingaleano.

Para tanto, a seleção das candidatas à escola deveria preencher características como: renúncia, submissão, bondade, ternura, inocência, obediência, doçura, entre outras. Esse ato de sujeição Que as candidatas, assim como as alunas, deveriam ter, representava regime de ordem, o poder disciplinar.

[...] Para fazer Enfermagem era preciso ser moça de boa família, era levado muito em consideração isso. Existia rigidez e disciplina na escola. Não só os professores, as aulas e as enfermeiras, mas tudo era controlado (Rosa dos Ventos)

O discurso presente nas falas anteriores, defendido nesse período, mostra um conceito de disciplina como uma arte de dominação do corpo, impondo uma relação de docilidade-utilidade, submissão representada, na época, pela mulher- mãe, mulher- filha, mulher-esposa, mulher-enfermeira ${ }^{(13)}$. A educação tinha como base o poder disciplinar, Que, conforme o mesmo autor, objetiva produzir corpos dóceis e produtivos, associado ao poder econômico e social. Esse discurso também esteve presente na fala de Brisa ao dizer em relação à aparência de alunos, ao comportamento,

[...] eles faziam uma boa seleção, era muito rigorosa. As alunas assumiam a responsabilidade, tinham uma boa aparência, uma atitude profissional, inclusive na economia hospitalar, de postura, de disciplina. (Brisa)

Os sujeitos, naquele momento da história, foram escolhidos para atender a uma relação de "docilidade-utilidade". Por mais Que desejassem inovar, mudar e, com certeza, houve avanços, mesmo Que pequenos, havia um "biopoder" Que, sutilmente, controlava os mecanismos de autonomia do Curso de Enfermagem, Que não acreditavam que pudesse ser alvo de concorrência para a medicina.

O biopoder, para Foucault, tem função diferente do disciplinamento. No caso do biopoder, para a enfermagem, está ligado aos grandes acontecimentos, fenômenos de massa, de grupos, como por exemplo, as competências da enfermeira, como sendo decisão de uma categoria. Entretanto, o disciplinamento, está diretamente ligado ao individuo, ao controle minucioso do corpo, Que se sujeita as forças externas, impondo uma relação de docilidade-utilidade, chamada de disciplina.

A disciplina fabrica assim corpos submissos e exercitados, corpos 'dóceis'. A disciplina aumenta as forças (em termos econômicos de utilidade) e diminui essas mesmas forças (em termos políticos de obediência). Em uma palavra: ela dissocia o poder do corpo; faz 
dele, por um lado, uma 'aptidão', uma 'capacidade' Que ela procura aumentar; e inverte, por outro lado, a energia, a potência Que poderia resultar disso, e faz dela uma relação de sujeição estrita ${ }^{(14)}$.

Em 1952, Waleska Paixão, então Diretora da escola de Enfermagem Anna Nery, do Rio de Janeiro, já Questionava no artigo: A formação moral da estudante de enfermagem, a rigidez nos internatos de Escolas de Enfermagem e o apego às tradições:

Seria aconselhável revermos as bases de nossas idéias de autoridade, Que muitas vezes hipertrofia e, mesmo desvirtuada, impõe à mocidade independente de hoje um fardo Quase insuportável e dificulta as relações harmoniosas do corpo docente e discente (15). $^{(15)}$.

Várias foram as situações ocorridas, conforme é citado em documentos históricos, em que as alunas eram punidas e até expulsas da escola por não aceitarem o regime disciplinar inflexível ${ }^{(16)}$, reforçado nas falas das entrevistadas,

\section{[... tínhamos disciplina (Rosa-dos-Ventos)}

[... a exigência era muito grande; era muito rigoroso (Brisa);

[... tinha uma cadência, realmente de disciplina, de moral, de ética. Tínhamos que não deixar dúvida sobre a nossa atitude (Sol)

Isso serviu para atender a uma ordem instituída, de Que para ser enfermeira era preciso ter atitude de docilidade, de extrema responsabilidade para não comprometer sua imagem Que estava sendo construída, na sociedade.

Alguns desses enunciados se legitimaram e se tornaram verdades, pois ainda estão incluídos nos nossos sistemas de avaliação da aluna, em campo de estágio, condutas, enfatizando atitudes, sua forma de apresentação e, até mesmo, em algumas situações, antes de iniciar estágio, as alunas recebem um modelo de uniforme, inclusive, definindo o mesmo tipo de tecido. São a vigilância e o controle submetendo corpos "dóceis", submissos às Questões econômicas e de utilidade ${ }^{(14)}$.

Nesse sentido, o poder disciplinar exercia e ainda exerce um meio de vigilância, cujo objetivo é gerir a vida das pessoas, controlálas em suas ações para torná-las dóceis, ou seja, pessoas economicamente produtivas e socialmente úteis ${ }^{(13)}$.

Hoje, o regime disciplinar já não é mais tão inflexível, a ponto de expulsão; entretanto, as micropenalidades disciplinares continuam atuais. Isto está presente em diferentes situações, muito sutis, como, em campo de estágio, pela forma de olhar do professor, das pequenas e grandes humilhações frente ao paciente, por parte do professor, o controle do uniforme, a forma de se apresentar, entre outros $^{(17)}$.

Ao percorrer esse caminho, o ensino de Graduação em Enfermagem esteve também alicerçado em mudanças curriculares Que atenderam a regimes de verdades instituídos por Questões políticas, econômicas e sociais e, em cada uma dessas, novos discursos foram produzidos.

Atualmente, nas Diretrizes Curriculares do Curso de Enfermagem, vê-se um grande desafio para o ensino, pois, ao mesmo tempo em Que se precisa formar um profissional generalista, também é necessário dar conta de uma necessidade política e econômica de atender, com competência e visibilidade, às várias especializações Que cada vez mais surgem no cenário da Saúde ${ }^{(18)}$.

Mas não podemos negar Que não houve avanços, como abordou Rosa dos Ventos ao dizer Que o

[...] ensino de Enfermagem está evoluindo, está indo pra frente. A enfermagem está sendo mais conhecida, principalmente os frutos da Enfermagem na sociedade e tudo, estão aparecendo mais positivamente, isso para nós, pra mim, que sou antiga é uma alegria, Quantas coisas Que eu trabalhava lá na época, lutava por aquilo, não conseguia; hoje já chega num lugar desses é uma coisa normal, é uma rotina. Que coisa boa, isso é uma beleza.

Quando ela coloca, com seu olhar no presente, mas voltado ao passado, Quer dizer Que muitas foram às escolhas, as lutas, na construção de outras práticas sociais Que fizeram produzir, além de novos conceitos, técnicas, o nascimento de novos sujeitos, novas práticas de liberdade, produzindo, assim, novas práticas de ensino ${ }^{(19)}$.

Reportando ao ensino de décadas anteriores, entre 1940 e 1960, período em Que as três personagens foram alunas, percebese Que os discursos permeados, nas três falas, são iguais, exemplificado na fala de Sol:

Nesta época, as enfermeiras só ministravam as aulas específicas à Enfermagem. Nós tínhamos professor de clínica de otorrino, inclusive fazíamos estágio no consultório particular dele e também na enfermaria, porque era assim, os professores eram também os coordenadores e chefes das cadeiras nas enfermarias. Então, o professor de oftalmo ou de otorrino, ele além de ser o coordenador, o chefe daquela enfermaria, onde nós fazíamos estágio, ele também nos levava para o consultório dele e vários professores (médicos) faziam isso. Então a nossa interação durante o estágio era muito também com esse professor, porQue nós o víamos sempre. Então nós tínhamos otorrino, uma disciplina, e a enfermagem otorrino era uma enfermeira Que dava. Outro exemplo era a Clínica Cirúrgica, Que era o cirurgião Que dava e a Enfermagem Cirúrgica era a enfermeira Que dava. As mesmas aulas do professor, nós tínhamos com a Enfermagem.

Na continuidade desse discurso, Rosa dos Ventos Que, além de compartilhar a mesma experiência de Sol, colocou os diferentes saberes que permeavam à época, "mais científico/menos científico":

Quanto ao ensino, naquela época, a parte de Enfermagem era dada por enfermeira. Mas a parte mais científica era dada pelos médicos. Tinha médico, por exemplo, de Anatomia, de Otorrinolaringologia, de Oftalmologia. Hoje as enfermeiras é Que fazem isso. As enfermeiras davam a parte de Enfermagem, de técnicas de Enfermagem, de Enfermagem Cirúrgica, Enfermagem Obstétrica, Enfermagem Pediátrica.

Brisa também trouxe a mesma experiência, ou seja, ela iniciou com um saber de domínio médico, sendo aos poucos compartilhado com enfermeiras docentes, até chegar aos tempos atuais, em Que as disciplinas relacionadas à Enfermagem são totalmente ministradas 
por enfermeiras. Entretanto, não rompemos ainda com o modelo biologicista, em que as disciplinas das Ciências Biológicas são totalmente ministradas por profissionais de outras Áreas.

[... o currículo atual muito fragmentado e os alunos tendo flashes das coisas. Eles não têm tempo de identificar o modelo Que está sendo aplicado, se é humanístico, holístico. Na nossa época, os estágios eram mais prolongados e a gente partia da teoria de Que conhecendo bem o modelo, ele seria capaz de transferir para a prática. Esta fragmentação não constrói o conhecimento e o corpo teórico para aluno desenvolver na sua práxis.

Porém, é preciso, não transformar as Diretrizes Curriculares em um "novo modelo" Que apresenta "novos nomes", como eixos temáticos, núcleos conceituais, mas que continua tendo, como pano de fundo, os mesmos modelos tradicionais de uma Pedagogia Positivista $^{(20)}$. Nessa linha de pensamento, é importante refletir sobre alguns Questionamentos:

Será Que, ao contarmos com o subsídio de muitas disciplinas, atuando convergentemente, num processo transdisciplinar articulado, podemos dar novos sentidos ao conhecimento? Que outras condições seriam necessárias para apoiar o desenvolvimento de tais propostas $^{(20)}$ ?

Além desses, acrescentam-se Quais são as vozes visíveis e as invisíveis Que estão norteando as Diretrizes do Curso de Graduação em Enfermagem? Que Enfermagem se está Querendo tornar visível? Que outros saberes e poderes irão se tramar? Quem se tornará invisível?

Outro ponto referendado por Sol e merecedor de análise é Quanto à interação professor/aluno, ao longo desses tempos:

No ensino de Enfermagem, entre ganhos e perdas, para mim prevalece ganhos, muito fortes, porQue os alunos estão, no meu ponto de vista, gradativamente desenvolvendo a interação com o professor, claro que o professor abre este espaço. Então, os recursos de ensino são muito fortes, nós temos uma literatura muito forte e a cultura social mudou muito, Quebrou aquele distanciamento hierárquico entre o adulto e o jovem.

Quando Sol nos coloca a relação aluno/professor de uma forma mais integradora, nos tempos atuais, ela nos sinaliza a constituição de novos sujeitos e a criação de novas práticas de liberdade. Esse olhar em Que ela se fundamenta, está alicerçado em sua trajetória, ao longo dos anos, como aluna e como docente e Que também esteve presente na fala das outras personagens.

Cita-se como exemplo uma experiência de Rosa dos Ventos, Quando aluna de Graduação em Enfermagem, em relação à rigidez e incompreensão da professora sobre uma situação vivenciada por ela, na década de 1940:

Uma vez, eu estava trabalhando, de noite, em plantão. Era estágio, foi o dia em Que mais trabalhei na minha vida, pois comecei às 7 h da manhã, passei todo dia, toda noite e fui acabar à I h da madrugada do outro dia, à Ih não, foi às 4h, eu me lembro, Que foram 2 I horas de trabalho corrido. Naquele dia, nós tínhamos uma prova, de doenças infecciosas e eu estava exausta. Cheguei lá com sono, exausta, sem cabeça pra fazer uma prova. Então fui falar com a Diretora; havia Diretora de ensino e Diretora de estágio. Explieuei para a Diretora de estágio e ela disse: por causa disso não pode fazer a prova? Sim, a Sra. tem condições. Eu podia ter estudado um pouQuinho na véspera, mas não tive condições, e ela não gostou e disse: 'No meu tempo, uma coisa dessas não impedia de fazer a prova, mas hoje as senhoras são muito mais [...] superficiais e pensou: mas, então ok! Precisamos marcar com o professor outro dia para fazer a prova. Mas repara só a rigidez, uma pessoa que trabalha 2 Ih corrido [...]

Ao procurar analisar este discurso, reporta-se aos tempos atuais e se trazem como exemplos alunos Que trabalham como técnicos/ auxiliares de enfermagem, muitas vezes, em dois empregos para sustentar um curso particular. Provavelmente também devem ter vivenciado essa situação. Será Que, os docentes, nos tempos atuais, estão abertos para essas Questões, cada vez mais presentes no meio acadêmico?

Essas práticas, assim como outras se traduzem, hoje, como um modo de inquietação, o Que se acredita ser salutar, pois são movimentos Que fazem a Enfermagem produzir novos saberes e encontrar estratégias para unir fios e desunir outros tantos que, ao longo dessa trajetória, permaneceram ou desejaram estar invisíveis ${ }^{(21)}$.

Dessa forma, é preciso colocar visível o Que ainda está oculto e, além disso, é importante não absolutizar em um único discurso, pois, desta forma, se estará fadada a não olhar além do que o texto Quer dizer, não contribuindo assim, para a (des)construção de múltiplos saberes.

\section{CONSIDERAÇÕES FINAIS}

A análise desenvolvida nesse estudo aponta saberes Que foram sendo constituídos na trajetória da enfermeira, a partir da década de 1950, no RS, sejam eles denominados de sujeitados, desqualificados, fragmentados, de lutas, científicos, entre outros. Nessa rota, esses saberes estiveram ancorados na construção históricos da profissão, imprimindo, no cotidiano atual, verdades consagradas, impenetráveis e mantenedoras de múltiplos modos de constituição da sua práxis profissional.

Nesses modos de constituição, o ensino de Graduação em Enfermagem, a partir da primeira escola no RS, iniciou a sua rota, pautada no fazer da Área da Enfermagem e no saber da Área médica. Aos poucos, foi incorporando práticas Que mudassem, em parte, esse fazer e saber, como a inclusão de somente enfermeiras ministrando conteúdos na Área das Ciências da Enfermagem. Entretanto, na Área das Ciências Biológicas, grande parte dos conteúdos ainda são ministrados por outros profissionais da Saúde.

Ao reportar-se à constituição histórica do ensino, em relação aos jogos de verdades, percebem-se avanços em alguns regimes de verdade, entre os Quais se poderia citar o currículo mais integrado Que busca articular teoria/prática sem fragmentação do saber, proporcionando ao aluno a tomada de decisão na resolução de problemas, com os rigores técnicos e científicos e a relação ensinoaprendizagem na Qual professor e aluno sejam sujeitos desse processo.

Entretanto, ainda merece reflexão, a necessária superação de um ensino fragmentado e em algumas situações, formador de corpos dóceis e disciplinados e a fragilidade da integração às políticas de Saúde.

Ao continuar trilhando, nesse espaço geográfico, encontram-se 
brechas, fissuras Que possibilitam outros jogos de verdades, no universo acadêmico, entre eles, mesmo que incipiente, a vivência de conceito ampliado de saúde e a articulação de saberes nessa Área e o desenvolvimento da integralidade do cuidado como um dos eixos norteadores nas práticas de saúde.

Ao apresentar um recorte do ensino de Enfermagem, a partir da década de 1950, no RS, outros acontecimentos se entrelaçaram como redes de saberes e poderes, (des)unindo fios e trazendo à luz outros enunciados Que permaneceram à sombra. Re-escrever o ensino de Enfermagem, permite reatualizar a prática, o acontecimento, como uma das formas de constituir essas verdades Que, como bem disse Foucault, não estão visíveis, muito menos, provêm, a priori, da teoria ${ }^{(8)}$. Ela se faz a partir do modo como se tratam e se instituem esses objetos, estratégias via-acontecimentos.

\section{REFERÊNCIAS}

1. Fallante BSC, Barreira IA. Significados da visita domiciliar realizada pelas enfermeiras de saúde pública nas décadas de 20 e 30. Esc Anna Nery Rev Enferm 1998; 2(3): 72-85.

2. Nery MES, Vanzin AS. Enfermagem no Rio Grande do Sul 135 anos de história. Porto Alegre: RM\&L; 2000.

3. Germano RM. Educação e ideologia da Enfermagem no Brasil. São Paulo: Cortez; 1993.

4. Universidade Federal do Rio Grande do Sul. Escola de Enfermagem. Histórico da Escola de Enfermagem da UFRGS. [citado em: 2005 fev 3]. Disponível em: http://www.ufrgs.br/ eenf/historico.htm

5. Rizzotto MLF. História da enfermagem e sua relação com a saúde pública. Goiânia: AB; 1999.

6. Ferreira MM, Amado J. Usos e abusos da História oral. Rio de Janeiro: Fundação Getúlio Vargas, 1996.

7. Foucault M. A ordem do discurso. $2^{\mathrm{a}}$ ed. São Paulo: Loyola; 2000.

8. Foucault M. Em Defesa da sociedade. São Paulo: Martins Fontes, 1999.

9. Carneiro VC. Profissionalização do professor de matemática: limites e possibilidades para a formação inicial [tese] Porto Alegre: Faculdade de Educação, Pontifícia Universitária do Rio Grande do Sul; 1999.

10. Foucault M. O sujeito e o poder. In: Rabinow P, Dreyfus H. Michel Foucault, uma trajetória filosófica - para além do estruturalismo e da hermenêutica. Rio de Janeiro: Florense Universitária; 1995.

11. Pesavento SI. História do Rio Grande do Sul. Porto Alegre:
Mercado Aberto; 1997.

12. Gallo E, Nascimento PC. Hegemonia, bloco histórico e movimento sanitário. In.: Teixeira SF, organizador. Reforma sanitária: em busca de uma teoria. São Paulo: Cortez; 1995.

13. Foucault M. Vigiar e punir. Rio de Janeiro: Vozes; 1999.

14. Foucault M. Microfísica do poder. Rio de Janeiro: Graal; 2001 .

15. Paixão $W$. A formação moral da estudante de enfermagem. Anais Enferm 1952; 4(1): 20-4.

16. Sauthier I, Barreira IA. As enfermeiras norte-americanas e o ensino da enfermagem na Capital do Brasil: 192 I-1931. Rio de Janeiro: Anna Nery/UFRJ; 1999.

17. Lunardi VL, Peter E, Gastaldo D. Enfermeiras submissas são éticas? Refletindo sobre a anorexia de poder. Rev Bras Enferm 2002; 55(2): 183-8.

18. Ministério da Educação e Cultura (BR). Conselho Nacional de Educação. Câmara de Educação Superior. Resolução CNE/CES $\mathrm{n}^{\circ} 3$, de sete de novembro de 2001. Institui Diretrizes Curriculares Nacionais do Curso de Graduação em Enfermagem. Brasília: Ministério da Educação e Cultura; 2001 .

19. Foucault M. A verdade e as formas jurídicas. Rio de Janeiro: Nau; 1999.

20. Meyer DE, Kruse MHL. Acerca de diretrizes curriculares e projetos pedagógicos: um início de reflexão. Rev Bras Enferm 2003; 56(4): 335-9.

21. Corbellini VL. Disciplinamento dos saberes como jogos de verdades no ensino de Graduação em Enfermagem [tese]. Porto Alegre: Faculdade de Educação, Pontifícia Universidade Católica do Rio Grande do Sul; 2005. 